\title{
A Case of Pituitary Germinoma Misdiagnosed as Lymphocytic Hypophysitis
}

\author{
Mohammad Ghorbani ${ }^{\mathrm{a}}$, Mahnaz Moradi ${ }^{\mathrm{b}}$, Mohammad Ebrahim Khamseh ${ }^{\mathrm{b}}$, \\ Mojtaba Malek ${ }^{c}$, Zahra Emami ${ }^{b}$, Katayon Gohari-moghadam ${ }^{\mathrm{d}}$, \\ Mehrnaz Ghavamipour ${ }^{\mathrm{b}}$, Nahid Hashemi Madani ${ }^{b}$, e
}

\begin{abstract}
Pituitary germinomas are difficult to be differentiated from lymphocytic hypophysitis due to similar clinical, radiological and even histological findings. However, it is of great importance to make the distinction between them because of different therapeutic approaches of the two diseases. We report a case of neurohypophysial germinoma who initially was misdiagnosed as lymphocytic hypophysitis. The patient was a 26-year-old man who first presented with central diabetes insipidus and subsequent pan-hypopituitarism. Magnetic resonance imaging (MRI) of the pituitary which first had shown mild pituitary enlargement, revealed a pituitary mass of unusual feature after 1 year. Pathological diagnosis of the lesion, biopsied through trans-sphenoidal route, was lymphocytic hypophysitis. Corticosteroid was initiated for him. Despite, intensive treatment clinical symptoms worsened and the patient developed visual field defect. Follow-up MRI revealed enlargement of the pituitary mass with suprasellar extension and involvement of optic chiasm. Surgical resection of the mass was performed, and the second histological examination confirmed the diagnosis of germinoma. Subsequently, the patient underwent radiotherapy, and complete remission was achieved; however, pan-hypopituitarism persisted. In conclusion, the possibility of neurohypophyseal germinoma should be considered in patients with the diagnosis of lymphocytic hypophysitis who do not respond to corticosteroid therapy.
\end{abstract}

Keywords: Germ cell tumor; Pituitary germinoma; Hypophysitis

Manuscript submitted July 31, 2018, accepted August 30, 2018

aDepartment of Neurosurgery and Neuro-Intervention, Firoozgar Hospital, Iran University of Medical Sciences (IUMS), Tehran, Iran

${ }^{b}$ Endocrine Research Center, Institute of Endocrinology and Metabolism, Iran University of Medical Sciences (IUMS), Tehran, Iran

${ }^{\mathrm{c} R}$ Research Center for Prevention of Cardiovascular Disease, Institute of Endocrinology and Metabolism, Iran University of Medical Sciences (IUMS), Tehran, Iran

dDepartment of the Pathology, AJA University of Medical Science, Tehran, Iran

${ }^{e}$ Corresponding Author: Nahid Hashemi Madani, Endocrine Research Center, Institute of Endocrinology and Metabolism, No. 10, Firoozeh St., Vali-asr Ave, Vali-asr Sq., Tehran, Iran. Email: nahid.hashemimadani@gmail.com

doi: https://doi.org/10.14740/jem530w

\section{Introduction}

Germ cell tumors (GCTs) are a group of heterogenous tumors [1], occurring at different anatomical sites [2]. Extra-gonadal GCTs, consisting of $1-5 \%$ of all GCTs [3], are commonly found in the mediastinum, central nervous system (CNS) and retroperitoneum [2]. Based on histology, the World Health Organization (WHO) has divided GCTs into two broad groups: germinomatous and non-germinomatous [1].

The majority of primary intracranial GCTs are germinomas [4-6], most commonly located in the pineal and suprasellar regions of the brain [7]. The pineal location is strongly associated with male sex $[5,6]$. Moreover, GCTs, primarily germinoma, occurs more frequently in men than in women [5], with a higher incidence rate among Caucasian [6]. The peak age at the time of diagnosis is between 10 and 21 years of age [4-6].

Clinical presentation of intracranial GCTs depends on the location and size of the tumor, and frequently includes diabetes insipidus (DI), pituitary failure, visual field defects and signs of increased intracranial pressure [4-7]. Pineal germinoma actually mimics clinical manifestations of other neoplastic, granulomatous, infectious and inflammatory diseases of the same origin [8]. On the other hand, neuroimaging studies cannot differentiate GCTs from other tumors, and therefore, the diagnosis usually requires histological confirmation. However, even the histological findings might be misleading [9].

In this report, we present a 26 -year-old man who presented with central DI, hypopituitarism and subsequent visual field defect due to germinoma mimicking lymphocytic hypophysitis both clinically and histologically.

\section{Case Report}

The patient is a 26-year-old man who was first admitted to our hospital, at the age of 23 years, with a history of polyuria, polydipsia and frontal headache since 2 years prior to admission. Based on clinical presentation, water deprivation test was performed and central DI was diagnosed for him. However, other endocrine assessments were normal and pituitary magnetic resonance imaging (MRI) showed mild pituitary gland and stalk enlargement with normal enhancement. Family history, drug history and physical examination including 


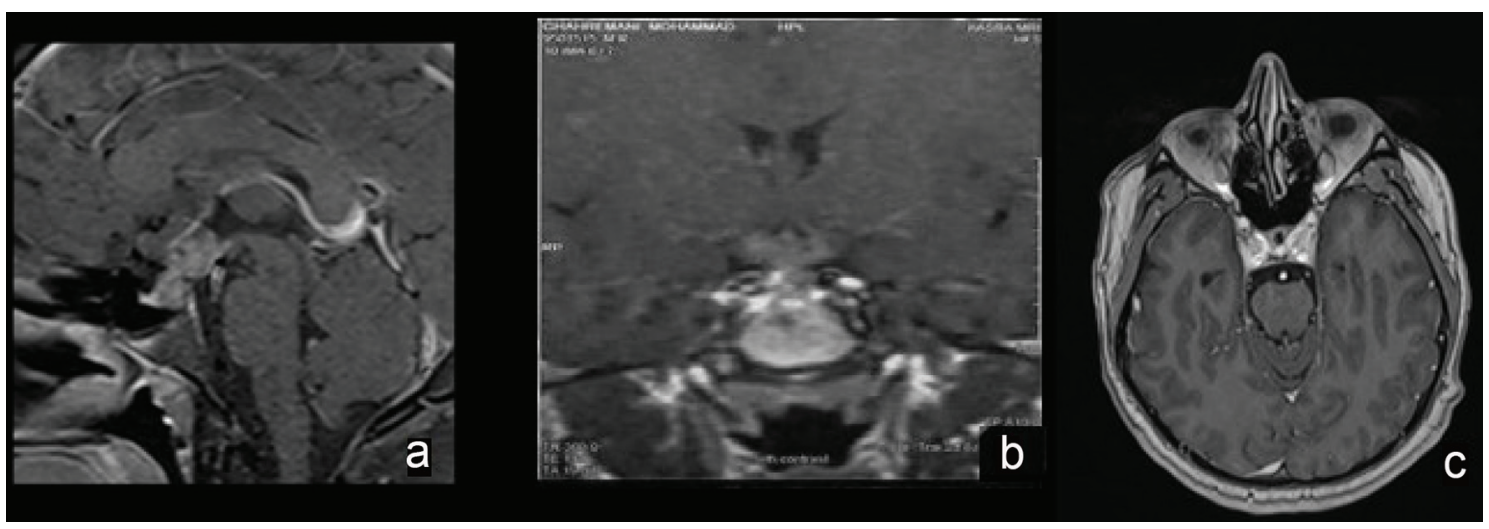

Figure 1. Cranial magnetic resonance imaging (MRI). Post-contrast images of sellar mass at the diagnosis (a and $b)$ and after radiotherapy (c).

neurological examination were unremarkable. Nasal desmopressin (DDAVP) was administrated, and he was discharged with the recommendation to perform pituitary MRI 6 months later. However, he did not refer to us until 2 years later when he gradually developed fatigue, decreased libido, impotence and loss of appetite. At that time, hormonal profile showed: thyroid-stimulating hormone (TSH) $2.5 \mu \mathrm{IU} / \mathrm{mL}$ (normal: $0.38-3.64 \mu \mathrm{IU} / \mathrm{mL}$ ), total thyroxine (TT4) $3 \mu / \mathrm{dL}$ (normal: $4.5-12.6 \mu / \mathrm{dL}$ ), prolactin (PRL) $74 \mathrm{ng} / \mathrm{ml}$ (normal: 4 - $15 \mathrm{ng} /$ $\mathrm{mL}$ ), luteinizing hormone $(\mathrm{LH})<1 \mathrm{IU} / \mathrm{L}$ (normal: 1.7 - 8.6 $\mathrm{IU} / \mathrm{L}$ ), follicle-stimulating hormone $(\mathrm{FSH})<1 \mathrm{IU} / \mathrm{L}$ (normal: 1.5 - $12.4 \mathrm{IU} / \mathrm{L}$ ), testosterone $0.2 \mathrm{ng} / \mathrm{mL}$ (normal: 2.8 - $8 \mathrm{ng} /$ $\mathrm{mL}$ ), insulin-like growth factor 1 (IGF-1) $112 \mathrm{ng} / \mathrm{mL}$ (normal: $89-276 \mathrm{ng} / \mathrm{mL})$ and cortisol $5.1 \mu / \mathrm{dL}(5-23 \mu / \mathrm{dL})$. Pituitary MRI revealed a soft tissue mass in the sellar region with extension to the floor of the third ventricle, marked thickening of pituitary stalk and loss of bright spot (Fig. 1a, b). With respect to unusual features of pituitary mass, the patient underwent an uncomplicated biopsy of the lesion through the endoscopic trans-sphenoidal route. The pituitary gland was infiltrated with small mature lymphocytes. Immunohistochemistry (IHC) study showed positive pituicytes for synaptophysin, and positive lymphocytes for CD45, CD20 and CD3. No immunoreaction with placental alkaline phosphatase (PLAP) was seen. The findings were compatible with lymphocytic hypophysitis (Fig. 2a). Cerebrospinal fluid (CSF) analysis for Mycobacterium tuberculosis, bacterial and fungal meningitis was nega- tive. All CSF tumor markers were negative: alpha-fetoprotein (AFP) $0.7 \mathrm{IU} / \mathrm{mL}$ (normal: $<6.9 \mathrm{IU} / \mathrm{mL}$ ), and beta-human chorionic gonadotropin $(\beta-\mathrm{HCG})<1 \mathrm{mIU} / \mathrm{mL}$ (normal: up to 2.6 $\mathrm{mIU} / \mathrm{ml}$ ). Serum angiotensin-converting enzyme (ACE) was also in normal range. Based on the diagnosis of lymphocytic hypophysitis, prednisolone $60 \mathrm{mg} /$ daily was initiated and replacement therapy with levothyroxine $(100 \mu$ daily), and testosterone ( $250 \mathrm{mg}$ monthly) was started. In spite of adherence to his medication, the patient gradually developed a decrease in visual acuity over a period of 5 months. Visual field assessment showed bi-temporal hemianopia. Subsequent MRI showed enlargement of sellar mass involving pituitary gland with suprasellar extension and involvement of optic chiasm. Thus, the second surgery was performed and the lesion was resected. The pituitary gland showed a hypercellular neoplastic growth composed of nests of large cells having high N/C and prominent nucleoli. In addition, stroma was infiltrated by small lymphocytes. IHC study revealed positive immunoreaction with C-kit and PLAP in neoplastic cells (Fig. 2b, c). No immunoreaction with CD45, synaptophysin and CD30 was seen. Thus, the diagnosis of germinoma with lymphocytic reaction was confirmed. After surgery, the patient received radiation therapy with a total dose of 25 Gy. One year after the completion of radiation therapy, MRI revealed complete resolution of the mass (Fig. 1c). Visual acuity and visual field became normal. However, central DI and hypopituitarism remained and need further treatment.
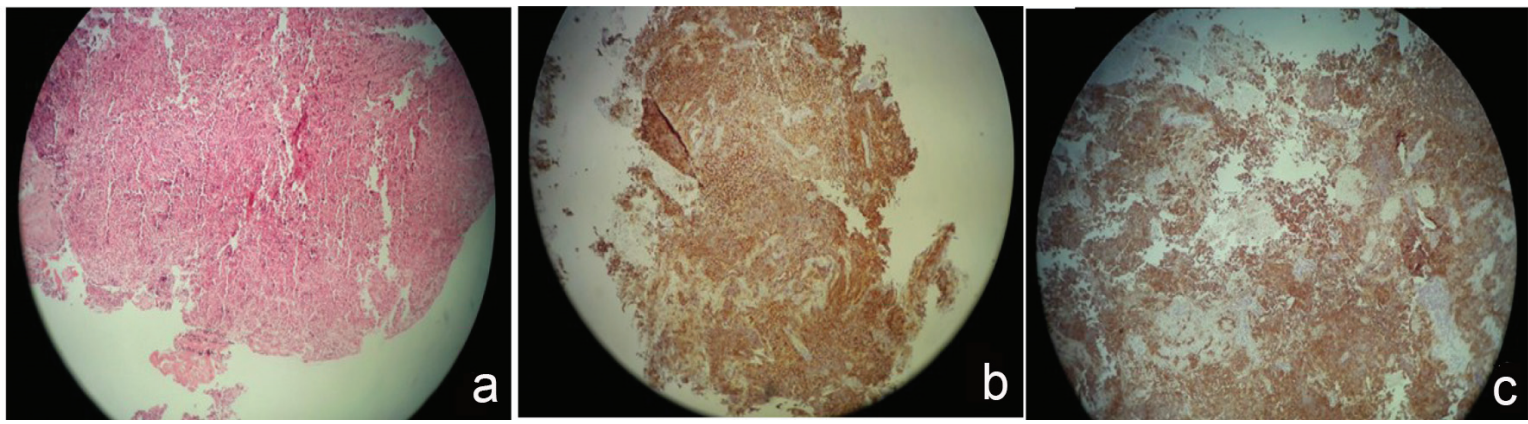

Figure 2. Pituitary histopathology. Heavy infiltrate of B lymphocytes compatible with lymphicytic hypophysitis (a); immunohistochemistry staining for c-kit (b) and PALP (c) highlighting germinoma's cell. 


\section{Discussion}

More than one-third of intracranial GCTs are germinoma [4, $6,10]$, often localized in the pineal gland and/or in suprasellar region. Pineal germinoma clinically presents with central DI, hypopituitarism and visual field defect, commonly seen in patients with sellar lesions other than germinoma $[8,11,12]$. Hypothalamic/pineal mass and stalk thickening are common radiological findings of germinoma [13, 14], which are not easily distinguishable from other pathological processes in this region. However, establishing a definitive diagnosis of a germinoma is quite important due to the pronounced differences in therapeutic options compared with other abnormal lesions found in this area such as lymphocytic hypophysitis. Nowadays, clinicians rely on tissue biopsy to make an accurate diagnosis before proceeding with further management, except in cases with elevated levels of tumor markers such as AFP and $\beta$-HCG [1]. High levels of these markers are associated with more malignant GCTs and indicate the presence of non-germinomatous elements [15]. However, pure germinomas seldom produce high levels of these tumor markers [15].

Histologically, germinoma represents a typical two-cell pattern. The tumor is composed of neoplastic cells mixed with small lymphocytic infiltration and may show fibro-inflammatory changes, including neoplastic cells $[16,17]$. However, the diagnosis of germinoma is more challenging due to the fact that both lymphocytic infiltration and granulomatous reaction are seen in inflammatory diseases such as different kinds of hypophysitis $[18,19]$.

This report presents the difficulties in differentiating various kinds of pituitary lesions due to common clinical, radiological and even histological findings. This 26-year-old man with lymphocytic infiltration of the pituitary gland was first treated as a case of lymphocytic hypophysitis leading to a delay in the diagnosis and appropriate management.

Lymphocytic and granulomatous hypophysitis are the most common histological forms of hypophysitis [19]. They can be idiopathic, secondary, or associated with systemic disorders [20]. The concept of secondary hypophysitis, first introduced by Sautner et al., describes an inflammatory lesion of the pituitary gland due to an extension of inflammation from an associated pathological process of the surrounding tissue like craniopharyngioma, prolactinoma or Rathke's cleft cyst [20, 21].

Lymphocytic hypophysitis, the most common form of hypophysitis, is associated with autoimmune disorders in $20-50 \%$ of cases [22-24]. In terms of the site of inflammation, lymphocytic hypophysitis is classified into two types: lymphocytic adenohypophysitis (LAH), and lymphocytic infundibuloneurohypophysitis (LINH). LAH, which occurs in the anterior pituitary, is more commonly seen in women, and is related to pregnancy or postpartum period, but also can occur in non-pregnant women and even in men [25]. LAH may present with complete or partial hypopituitarism, headache and visual disorders, mimicking other pituitary masses [26]. The pattern of hormone loss in LAH, including isolated adrenocorticotropic hormone (ACTH) deficiency or combined adrenal and/or thyroid deficiencies in the presence of normal gonadal function [19], is in contrast to what occurs in the presence of a pituitary mass [26].
LINH first reported by Imura et al [27] is the other type of lymphocytic hypophysitis. Inflammation occurring in the posterior pituitary and/or pituitary stalk is a leading cause of DI [27]. The histological findings of both types of lymphocytic hypophysitis consist of diffuse infiltration of $\mathrm{T}$ and $\mathrm{B}$ lymphocytes, plasma cells and varying degrees of fibrosis [19]. A similar pattern of lymphocytic infiltration seen in germinomas [16] leads to misdiagnosing of pineal germinoma as lymphocytic hypophysitis.

To the best of our knowledge, nine cases of lymphocytic hypophysitis secondary to germinoma misdiagnosed as primary LAH have been reported before [28-30] (Table 1). In most of them, the diagnosis of LAH was based on histological findings, and consequently, glucocorticoid was the initial treatment. The unfavorable clinical follow-up followed by second pituitary biopsy leads to the diagnosis of germinoma. All these cases presented with DI and panhypopituitarism. In some of them, first MRI was normal [12, 31, 32]. However, immunostaining for PLAP or c-kit, performed either on the first [12] or on the follow-up biopsy, leads to the diagnosis of germinoma. Interestingly, for most of them, the final diagnosis takes a long time to be established.

Germinomas are highly immunogenic tumors, showing varying degrees of lymphocytic infiltration [16]. The reason for heavy lymphoid infiltration in germinoma is not well known. However, Gutenberg et al reported a case of germinoma masking by lymphocytic hypophysitis. An immunological study in this case showed that germinoma cells express antigens which can be recognizable by patient's serum antibodies [33]. However, tumors infiltrating lymphocytes favorably affect the clinical outcome of germinomas [34].

The typical histological form of germinoma called two-cell pattern type consists of small lymphocytic infiltration and large neoplastic germ cells, and the other less common form consists mainly of granulomatous inflammation and fibrous tissue [16, 34]. Endoscopic neurosurgical techniques, as safe methods for tumor biopsy $[35,36]$, obtain biopsy specimen as small as 2 $\mathrm{mm}$ in its greatest dimension that may fail to show germinoma's malignant cell [17]. The histological diagnosis of germinoma is even more difficult when most of the specimen contains fibrous tissue and granulomatous reaction [16]. This acceptable sampling error, even by stereotactic technique, can be minimized in the hands of an experienced neurosurgeon through selecting the appropriate site of the biopsy as well as obtaining several numbers of specimens. In addition, immunohistochemical studies of PLAP are recommended in the cases of clinical suspicion with nonspecific histological finding $[12,37]$.

In summary, as sellar germinomas show clinical, radiological and even histological finding in common with other pituitary lesions especially lymphocytic hypophysitis, the prolonged symptomatic period prior to the definite diagnosis is common. Furthermore, a final diagnosis of germinoma required immunohistochemical study of multiple specimens obtained from the pituitary lesion.

\section{Acknowledgments}

We really appreciate our patient for his co-operation. 


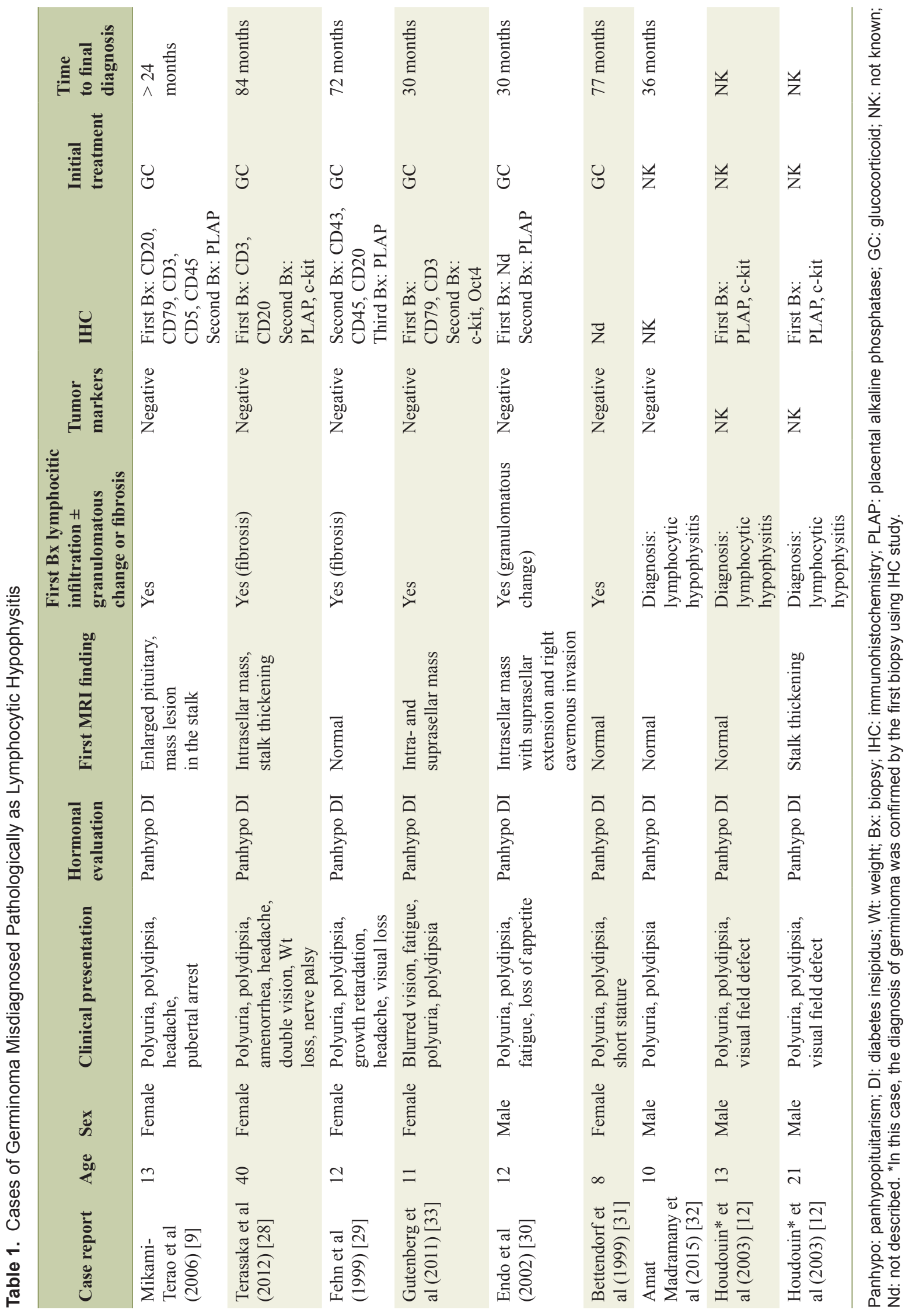




\section{Disclosure}

The authors report no conflict of interest concerning the materials or methods used in this study or the findings specified in this paper.

\section{References}

1. Louis DN, Ohgaki H, Wiestler OD, Cavenee WK, Burger PC, Jouvet A, Scheithauer BW, et al. The 2007 WHO classification of tumours of the central nervous system. Acta Neuropathol. 2007;114(2):97-109.

2. Gao Y, Jiang J, Liu Q. Extragonadal malignant germ cell tumors: a clinicopathological and immunohistochemical analysis of 48 cases at a single Chinese institution. Int J Clin Exp Pathol. 2015;8(5):5650-5657.

3. McKenney JK, Heerema-McKenney A, Rouse RV. Extragonadal germ cell tumors: a review with emphasis on pathologic features, clinical prognostic variables, and differential diagnostic considerations. Adv Anat Pathol. 2007;14(2):69-92.

4. Jennings MT, Gelman R, Hochberg F. Intracranial germcell tumors: natural history and pathogenesis. J Neurosurg. 1985;63(2):155-167.

5. Goodwin TL, Sainani K, Fisher PG. Incidence patterns of central nervous system germ cell tumors: a SEER Study. J Pediatr Hematol Oncol. 2009;31(8):541-544.

6. Villano JL, Propp JM, Porter KR, Stewart AK, ValyiNagy T, Li X, Engelhard HH, et al. Malignant pineal germ-cell tumors: an analysis of cases from three tumor registries. Neuro Oncol. 2008;10(2):121-130.

7. Echevarria ME, Fangusaro J, Goldman S. Pediatric central nervous system germ cell tumors: a review. Oncologist. 2008;13(6):690-699.

8. Guzzo MF, Bueno CB, Amancio TT, Rosemberg S, Bueno C, Arioli EL, Glezer A, et al. An intrasellar germinoma with normal tumor marker concentrations mimicking primary lymphocytic hypophysitis. Arq Bras Endocrinol Metabol. 2013;57(7):566-570.

9. Mikami-Terao Y, Akiyama M, Yanagisawa T, TakahashiFujigasaki J, Yokoi K, Fukuoka K, Sakuma M, et al. Lymphocytic hypophysitis with central diabetes insipidus and subsequent hypopituitarism masking a suprasellar germinoma in a 13-year-old girl. Childs Nerv Syst. 2006;22(10):1338-1343.

10. Matsutani M, Sano K, Takakura K, Fujimaki T, Nakamura O, Funata N, Seto T. Primary intracranial germ cell tumors: a clinical analysis of 153 histologically verified cases. J Neurosurg. 1997;86(3):446-455.

11. Reisch N, Kuhne-Eversmann L, Franke D, Beuschlein F, Mueller-Lisse UG, Reincke M, Seissler J. Intracranial germinoma as a very rare cause of panhypopituitarism in a 23-year old man. Exp Clin Endocrinol Diabetes. 2009;117(7):320-323.

12. Houdouin L, Polivka M, Henegar C, Blanquet A, Delalande O, Mikol J. [Pituitary germinoma and lymphocytic hypophysitis: a pitfall. Report of two cases]. Ann Pathol.
2003;23(4):349-354

13. Shankar S, Wu X, Kalra VB, Huttner AJ, Malhotra A. Ectopic intracranial germinoma. J Clin Neurosci. 2016;31:192-195.

14. Mootha SL, Barkovich AJ, Grumbach MM, Edwards MS, Gitelman SE, Kaplan SL, Conte FA. Idiopathic hypothalamic diabetes insipidus, pituitary stalk thickening, and the occult intracranial germinoma in children and adolescents. J Clin Endocrinol Metab. 1997;82(5):1362-1367.

15. Horowitz MB, Hall WA. Central nervous system germinomas. A review. Arch Neurol. 1991;48(6):652-657.

16. Utsuki S, Oka H, Tanizaki Y, Kondo K, Kawano N, Fujii K. Pathological features of intracranial germinomas with reference to fibrous tissue and granulomatous change. Brain Tumor Pathol. 2005;22(1):9-13.

17. Kraichoke S, Cosgrove M, Chandrasoma PT. Granulomatous inflammation in pineal germinoma. A cause of diagnostic failure at stereotaxic brain biopsy. Am J Surg Pathol. 1988;12(9):655-660.

18. Leung GK, Lopes MB, Thorner MO, Vance ML, Laws ER, Jr. Primary hypophysitis: a single-center experience in 16 cases. J Neurosurg. 2004;101(2):262-271.

19. Tashiro T, Sano T, Xu B, Wakatsuki S, Kagawa N, Nishioka H, Yamada S, et al. Spectrum of different types of hypophysitis: a clinicopathologic study of hypophysitis in 31 cases. Endocr Pathol. 2002;13(3):183-195.

20. Sautner D, Saeger W, Ludecke DK, Jansen V, Puchner MJ. Hypophysitis in surgical and autoptical specimens. Acta Neuropathol. 1995;90(6):637-644.

21. Flanagan DE, Ibrahim AE, Ellison DW, Armitage M, Gawne-Cain M, Lees PD. Inflammatory hypophysitis - the spectrum of disease. Acta Neurochir (Wien). 2002;144(1):47-56.

22. Bevan JS, Othman S, Lazarus JH, Parkes AB, Hall R. Reversible adrenocorticotropin deficiency due to probable autoimmune hypophysitis in a woman with postpartum thyroiditis. J Clin Endocrinol Metab. 1992;74(3):548552.

23. Sobrinho-Simoes M, Brandao A, Paiva ME, Vilela B, Fernandes E, Carneiro-Chaves F. Lymphoid hypophysitis in a patient with lymphoid thyroiditis, lymphoid adrenalitis, and idiopathic retroperitoneal fibrosis. Arch Pathol Lab Med. 1985;109(3):230-233.

24. Li JY, Lai PH, Lam HC, Lu LY, Cheng HH, Lee JK, Lo YK. Hypertrophic cranial pachymeningitis and lymphocytic hypophysitis in Sjogren's syndrome. Neurology. 1999;52(2):420-423.

25. Gagneja H, Arafah B, Taylor HC. Histologically proven lymphocytic hypophysitis: spontaneous resolution and subsequent pregnancy. Mayo Clin Proc. 1999;74(2):150154.

26. Cosman F, Post KD, Holub DA, Wardlaw SL. Lymphocytic hypophysitis. Report of 3 new cases and review of the literature. Medicine (Baltimore). 1989;68(4):240-256.

27. Imura H, Nakao K, Shimatsu A, Ogawa Y, Sando T, Fujisawa I, Yamabe H. Lymphocytic infundibuloneurohypophysitis as a cause of central diabetes insipidus. N Engl J Med. 1993;329(10):683-689.

28. Terasaka S, Kawabori M, Kobayashi H, Murata J, Kan- 
no H, Tanaka S, Houkin K. Neurohypophyseal germinoma with abundant fibrous tissue. Brain Tumor Pathol. 2012;29(1):58-62.

29. Fehn M, Bettendorf M, Ludecke DK, Sommer C, Saeger W. Lymphocytic hypophysitis masking a suprasellar germinoma in a 12-year-old girl - a case report. Pituitary. 1999;1(3-4):303-307.

30. Endo T, Kumabe T, Ikeda H, Shirane R, Yoshimoto T. Neurohypophyseal germinoma histologically misidentified as granulomatous hypophysitis. Acta Neurochir (Wien). 2002;144(11):1233-1237.

31. Bettendorf M, Fehn M, Grulich-Henn J, Selle B, Darge K, Ludecke DK, Heinrich UE, et al. Lymphocytic hypophysitis with central diabetes insipidus and consequent panhypopituitarism preceding a multifocal, intracranial germinoma in a prepubertal girl. Eur J Pediatr. 1999;158(4):288-292.

32. Amat Madramany A, Gastaldo Simeon E, Revert Ventura A, Escobar Hoyos LA, Riesgo Suarez P. [Importance of long-term follow-up of diabetes insipidus; from lymphocytic hypophysitis to germinoma]. An Pediatr (Barc). 2015;82(1):e108-112.

33. Gutenberg A, Bell JJ, Lupi I, Tzou SC, Landek-Salgado MA, Kimura $\mathrm{H}, \mathrm{Su}$ J, et al. Pituitary and systemic autoimmunity in a case of intrasellar germinoma. Pituitary. 2011;14(4):388-394.

34. Utsuki S, Oka H, Tanizaki Y, Kondo K, Kawano N, Fujii K. Histological features of intracranial germinomas not disappearing immediately after radiotherapy. Neurol Med Chir (Tokyo). 2006;46(9):429-433.

35. Reddy AT, Wellons JC, 3rd, Allen JC, Fiveash JB, Abdullatif $\mathrm{H}$, Braune KW, Grabb PA. Refining the staging evaluation of pineal region germinoma using neuroendoscopy and the presence of preoperative diabetes insipidus. Neuro Oncol. 2004;6(2):127-133.

36. Wenger $\mathrm{M}$, Lovblad KO, Markwalder R, Taub E. Late recurrence of pineal germinoma. Surg Neurol. 2002;57(1):34-39; discussion 39-40.

37. Konno S, Oka H, Utsuki S, Kondou K, Tanaka S, Fujii K, Yagishita S. Germinoma with a granulomatous reaction. Problems of differential diagnosis. Clin Neuropathol. 2002;21(6):248-251. 